\title{
Article \\ Root-Associated Entomopathogenic Fungi Modulate Their Host Plant's Photosystem II Photochemistry and Response to Herbivorous Insects
}

\author{
Julietta Moustaka*(D), Nicolai Vitt Meyling (D) and Thure Pavlo Hauser*(D)
}

Citation: Moustaka, J.; Meyling, N.V.; Hauser, T.P. Root-Associated Entomopathogenic Fungi Modulate Their Host Plant's Photosystem II Photochemistry and Response to Herbivorous Insects. Molecules 2022, 27, 207. https://doi.org/ 10.3390/molecules27010207

Academic Editor: Rui Fausto

Received: 20 November 2021

Accepted: 26 December 2021

Published: 29 December 2021

Publisher's Note: MDPI stays neutral with regard to jurisdictional claims in published maps and institutional affiliations.

Copyright: (C) 2021 by the authors. Licensee MDPI, Basel, Switzerland. This article is an open access article distributed under the terms and conditions of the Creative Commons Attribution (CC BY) license (https:// creativecommons.org/licenses/by/ $4.0 /)$.
Department of Plant and Environmental Sciences, University of Copenhagen, Thorvaldsensvej 40, 1871 Frederiksberg, Denmark; nvm@plen.ku.dk

* Correspondence: moustaka@plen.ku.dk (J.M.); tpha@plen.ku.dk (T.P.H.)

\begin{abstract}
The escalating food demand and loss to herbivores has led to increasing interest in using resistance-inducing microbes for pest control. Here, we evaluated whether root-inoculation with fungi that are otherwise known as entomopathogens improves tomato (Solanum lycopersicum) leaflets' reaction to herbivory by Spodoptera exigua (beet armyworm) larvae using chlorophyll fluorescence imaging. Plants were inoculated with Metarhizium brunneum or Beauveria bassiana, and photosystem II reactions were evaluated before and after larval feeding. Before herbivory, the fraction of absorbed light energy used for photochemistry $\left(\Phi_{P S I I}\right)$ was lower in M. brunneum-inoculated than in control plants, but not in B. bassiana-inoculated plants. After herbivory, however, $\Phi_{P S I I}$ increased in the fungal-inoculated plants compared with that before herbivory, similar to the reaction of control plants. At the same time, the fraction of energy dissipated as heat $\left(\Phi_{N P Q}\right)$ decreased in the inoculated plants, resulting in an increased fraction of nonregulated energy loss $\left(\Phi_{N O}\right)$ in $M$. brunneum. This indicates an increased singlet oxygen $\left({ }^{1} \mathrm{O}_{2}\right)$ formation not detected in B. bassiana-inoculated plants, showing that the two entomopathogenic fungi differentially modulate the leaflets' response to herbivory. Overall, our results show that $M$. brunneum inoculation had a negative effect on the photosynthetic efficiency before herbivory, while B. bassiana inoculation had no significant effect. However, S. exigua leaf biting activated the same compensatory PSII response mechanism in tomato plants of both fungal-inoculated treatments as in control plants.
\end{abstract}

Keywords: photosynthetic efficiency; compensatory process; chlorophyll fluorescence imaging; herbivory costs; non-photochemical quenching; singlet oxygen; Solanum lycopersicum; Spodoptera exigua; Metarhizium brunneum; Beauveria bassiana

\section{Introduction}

The escalating demand for food supply worldwide and the necessity of more sustainable agricultural practices [1,2] has led to an increasing interest in the application of beneficial microbes in agriculture $[3,4]$. Entomopathogenic fungi are identified by their ability to infect insects and produce spores that can grow, germinate, and spread from the cadaver [5,6]. Most literature on entomopathogenic fungi has focused on their use for biocontrol of multiple arthropod agricultural pests [7-9]. Recently, however, researchers have discovered that these fungi can also associate with many plant species as rhizosphere colonizers or endophytes, and that associations of plants with entomopathogenic fungi can promote their defense against phytopathogens [5,10-13] and insect pests [3,14-19], depending on the isolate and the plant species. Thus, several studies in the last decades have focused on the effect of entomopathogenic fungi on plants' defense and other plant properties [3,14-20]. These symbiotic effects suggest that entomopathogenic fungi may be exceptional tools for Integrated Pest Management (IPM) strategies [6,10].

The precise mechanism of the defense promotion in this symbiotic relationship is not fully understood. It can involve induction or priming of systemic resistance and production 
of defense compounds, in addition to increased nutrient availability for the plant. Thus, it has been shown that five species of Metarhizium and the species Beauveria bassiana can transfer insect-derived nitrogen to their plant hosts [21,22]; in return, plants provide the entomopathogenic fungi with photosynthates [23].

The ability of a plant to maintain its photosynthetic efficiency, even when attacked by antagonists, is crucial for the plant's defense and compensatory responses [24,25]. Moreover, non-photochemical quenching (NPQ) is considered as the principal photoprotective mechanism in plants that dissipates excess light energy as heat and protects light reaction under biotic and abiotic stress conditions, preventing the formation of reactive oxygen species (ROS) [26-29]. NPQ is involved in the mechanism of plant acclimation to biotic or abiotic stress and has been suggested to be a major component of the systemic acquired resistance [30-32]. Associations of plants with another group of root-associated fungi, mycorrhizal fungi, are known to increase the photosynthetic efficiency of plants [33-38]; several studies have addressed how this is affected by environmental stress $[35,37,38]$, including herbivore attack [39]. The effects of root-associated entomopathogenic fungi on plant's photosynthesis are far less studied. When durum wheat (Triticum durum L. cv. Calero) was inoculated with Metarhiziumbrunneum, net photosynthesis and chlorophyll concentrations increased [40,41]. Inoculations of date palms (Phoenix dactylifera L.) with B. bassiana upregulated genes encoding photosynthesis-related proteins [42]. Furthermore, inoculation of potato (Solanum tuberosum) with encapsulated M. brunneum increased the maximum $(\mathrm{Fv} / \mathrm{Fm})$ and the effective quantum yield $\left(\Phi_{P S I I}\right)$ of photosystem II in poor nutrient conditions but not in fertilized soil [43]. However, to our knowledge no studies have shown that the root association with entomopathogenic fungi affects the plant photosynthetic response to insect herbivory.

In a previous study [44], we showed that photosynthetic efficiency of tomato leaves increased in response to biting by Spodoptera exigua larvae (Húbner; beet armyworm) in neighboring leaf parts, suggesting a compensatory response. Tomato, Solanum lycopersicum, is one of the commonly cultivated horticultural crops $[45,46]$ that is susceptible to a variety of insect pests $[3,47,48]$. One of these is $S$. exigua, a polyphagous species that consumes a wide variety of plant hosts, including many crops, causing severe economic losses [49-51].

In the present study, we investigate whether root-inoculations with two different entomopathogenic fungi, Metarhizium brunneum and Beauveria bassiana, increase the photosynthetic efficiency of tomato leaves, and whether the associations improve the leaf's photosynthetic response to short-term herbivory by S. exigua larvae. For this, we used chlorophyll fluorescence imaging analysis, which allowed us to distinguish the localized leaf response at the feeding spots and in the other leaflet areas.

\section{Results}

\subsection{Comparison of Untreated Control Plants with Treated (Triton X) Control Plants}

We used two different control treatments, an untreated control where the inoculum only contained tap water and a treated control inoculated with Triton X $0.05 \%$. No significant difference was detected between the two controls for quantum yield of PSII photochemistry $\left(\Phi_{P S I I}\right)$, quantum yield of regulated non-photochemical energy loss in PSII $\left(\Phi_{N P Q}\right)$, non-photochemical quenching (NPQ), electron transport rate (ETR), and excess excitation energy $(E X C)$. For these parameters, values for the two control treatments were merged in subsequent analyses. The two control treatments did differ significantly for quantum yield of nonregulated energy loss in PSII $\left(\Phi_{N O}\right)$ and photochemical quenching $\left(\mathrm{q}_{\mathrm{P}}\right)$ before herbivory, where $\Phi_{N O}$ and $\mathrm{q}_{\mathrm{P}}$ were $8 \%$ and $15 \%$ lower in the treated control, respectively (Table S1). These values were not merged for the two control treatments in the analyses. 


\subsection{Effect of Root-Associated Entomopathogenic Fungi on Light Energy Distribution of} Photosystem II before and after Herbivory

\subsubsection{Before Herbivory}

The absorbed light energy in PSII is used either for photochemistry $\left(\Phi_{P S I I}\right)$, is photoprotectively dissipated as heat $\left(\Phi_{N P Q}\right)$, or is nonregulated loss $\left(\Phi_{N O}\right)$. The sum of these three fractions adds to unity [52].

In M. brunneum-inoculated tomato plants, the fraction of energy used for photochemistry $\left(\Phi_{P S I I}\right)$ decreased by $15 \%$ compared with that of control plants (Figure 1a; Table S2). At the same time, the fraction energy dissipated as heat $\left(\Phi_{N P Q}\right)$ increased by $12 \%$ compared with control (Figure 1b; Table S2), consequently, having an increase of $8 \%$ of the fraction of energy that is lost nonregulated in PSII $\left(\Phi_{N O}\right)$, compared with the untreated (Figure 2; Table S3). However, there was no difference in $\Phi_{N O}$ compared with the treated control (Figure 2; Table S3).

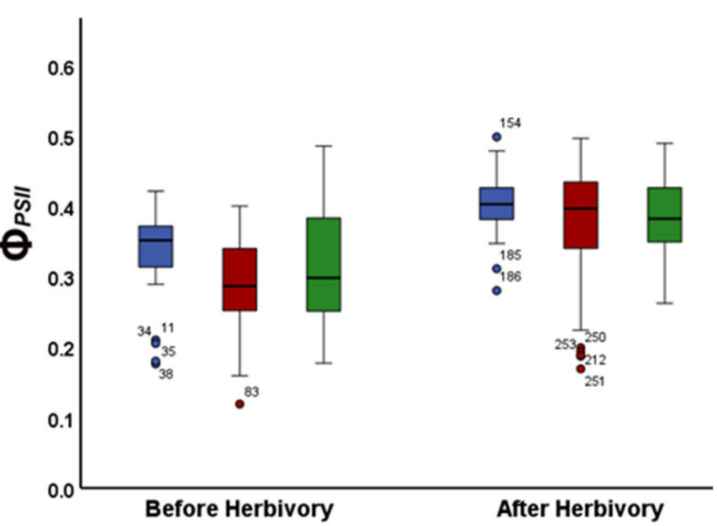

(a)

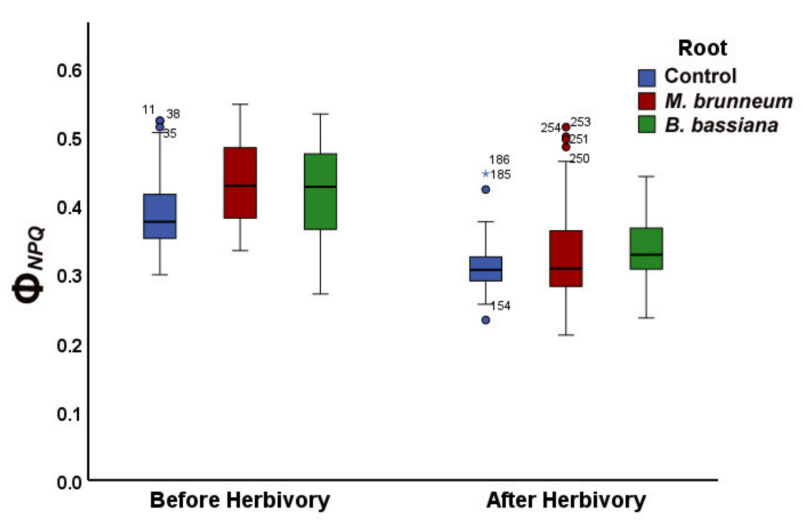

(b)

Figure 1. Changes in PSII quantum yields, (a) effective quantum yield of photochemistry (ФPSII), and (b) regulated non-photochemical energy loss ( $\Phi$ NPQ) in tomato leaflets before and immediately after herbivory $15 \mathrm{~min}$ of insect feeding, shown for untreated and treated controls (combined, blue), M. brunneum-inoculated plants (red), and B. bassiana-inoculated plants (green). Boxes and whiskers indicate the minimum, first quartile, median, third quartile and maximum, circles and asterisks indicate outliers, for statistical significance, see Supplementary Table S2.

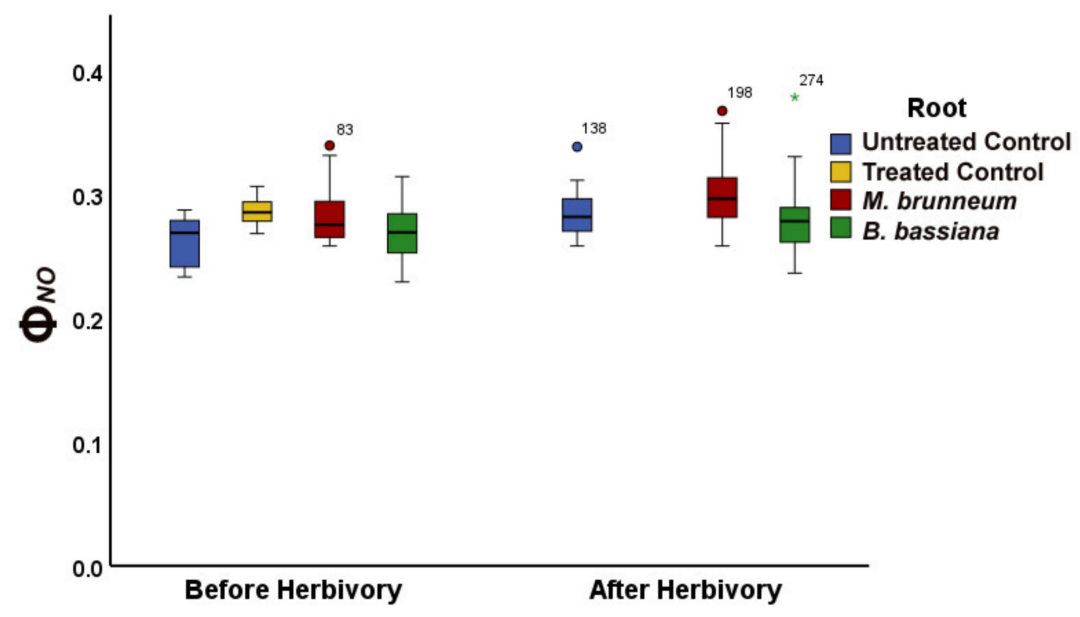

Figure 2. Nonregulated energy loss $(\Phi N O)$ of tomato leaflets before and immediately after insect feeding, from before to after herbivory, shown for untreated and treated controls (blue and yellow; or combined in blue). M. brunneum-inoculated plants (red); B. bassiana-inoculated plants (green). Boxes and whiskers explained in Figure 1. For statistical significances, see Supplementary Table S3. 
In B. bassiana-inoculated plants, the fraction of absorbed light energy used for photochemistry $\left(\Phi_{P S I I}\right)$ did not differ from controls, whereas the regulated energy loss $\left(\Phi_{N P Q}\right)$ was $9 \%$ higher and the nonregulated loss $\left(\Phi_{N O}\right)$ was $6 \%$ lower than the treated control plants (Figures 1a,b and 2; Tables S2 and S3) but had no difference compared with untreated control plants (Figure 2; Table S3).

\subsubsection{After Herbivory}

After herbivory, the fraction of absorbed light energy used for photochemistry $\left(\Phi_{P S I I}\right)$ did not differ between treatments (Figures 1a and 3a; Table S2). In B. bassiana-inoculated plants, the regulated and nonregulated energy loss $\left(\Phi_{N P Q}\right.$ and $\left.\Phi_{N O}\right)$ was $7 \%$ higher and $2 \%$ lower than in control plants, respectively. $\Phi_{N P Q}$ and $\Phi_{N O}$ were $3 \%$ higher and $6 \%$ lower in B. bassiana-inoculated than in M. brunneum-inoculated plants, respectively (Figures $1 b$ and $3 b$; Table S2).

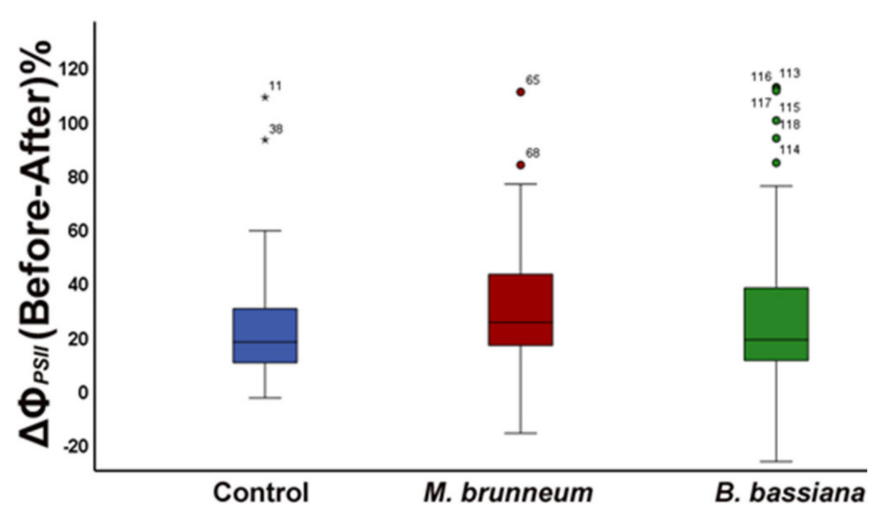

(a)

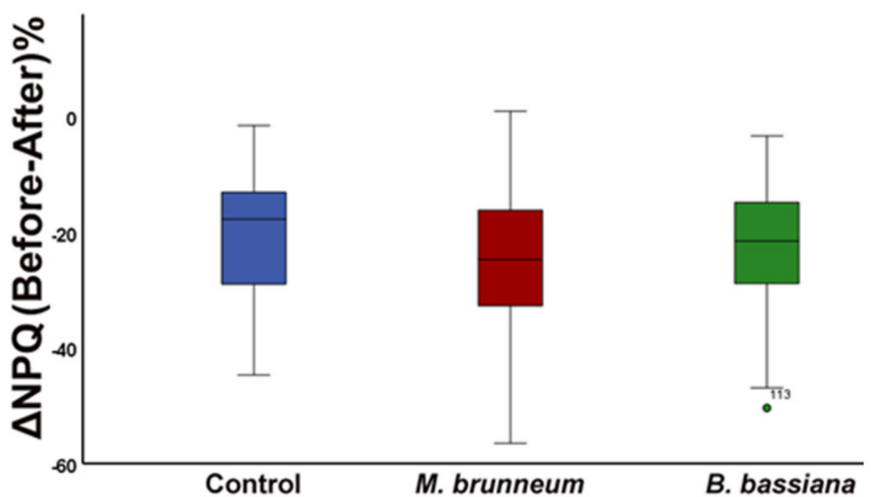

(b)

Figure 3. Difference of Before-After herbivory, expressed as percentage change, in the fraction of absorbed light energy (a) used for photochemistry $\left(\Phi_{P S I I}\right)$ and $(\mathbf{b})$ dissipated as heat $\left(\Phi_{N P Q}\right)$, shown for control plants (blue, untreated and treated combined), M. brunneum-inoculated (red), and B. bassiana-inoculated plants (green). Boxes and whiskers explained in Figure 1.

In M. brunneum-inoculated plants, the fraction of absorbed light energy used for photochemistry ( $\left.\Phi_{\text {PSII }}\right)$ increased by $32 \%$ compared with that before herbivory (Figures 1a and 3a; Table S2), while the fraction dissipated as heat $\left(\Phi_{N P Q}\right)$ decreased $22 \%$ and the fraction of nonregulated heat loss $\left(\Phi_{N O}\right)$ increased $5 \%$ (Figures $1 \mathrm{~b}, 2,3 \mathrm{~b}$, and 4; Tables S2 and S3).

In B. bassiana-inoculated plants, $\Phi_{P S I}$ increased compared with before herbivory by $24 \%$ (Figures $1 \mathrm{a}$ and 3a; Table S2). Simultaneously, $\Phi_{N P Q}$ decreased by $19 \%$ (Figures $1 \mathrm{~b}$ and 3b; Table S2) but without any difference in the amount of non-regulated energy loss $\left(\Phi_{N O}\right)$ compared with before herbivory (Figures 2 and 4; Table S3).

\subsection{Effect of Root-Associated Entomopathogenic Fungi on the other Chlorophyll Fluorescence Parameters before and after Herbivory}

\subsubsection{Before Herbivory}

In M. brunneum-inoculated plants, the non-photochemical quenching (NPQ) was $9 \%$ higher than in control plants, resulting in a 15\% decreased electron transport rate (ETR), possibly due to the decreased (22\%) fraction of open reaction centers (qP) (Figures 5a,b and 6a; Tables S3 and S4). At the same time, the excess excitation energy (EXC) increased by $12 \%$ compared with that of control plants (Figure 6b; Table S5). 


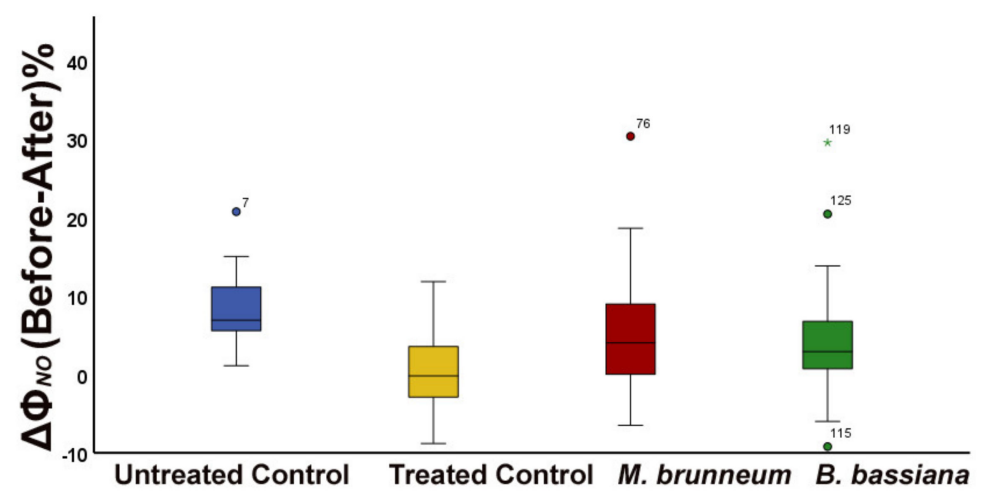

Figure 4. Difference of Before-After herbivory in the fraction of absorbed light energy lost nonregulated $\left(\Phi_{N O}\right)$, expressed as percentage change, shown for untreated and treated control plants (blue and yellow), M. brunneum-inoculated (red), and B. bassiana-inoculated plants (green). Boxes and whiskers explained in Figure 1.

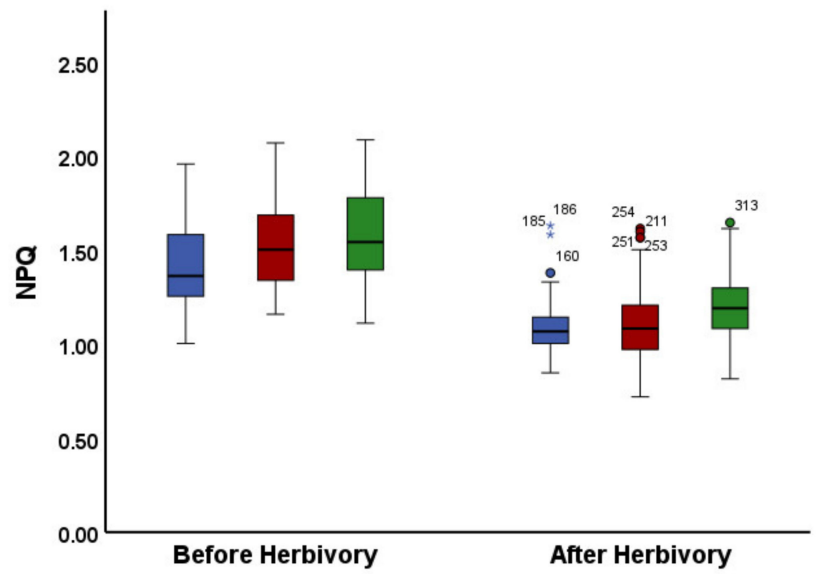

(a)

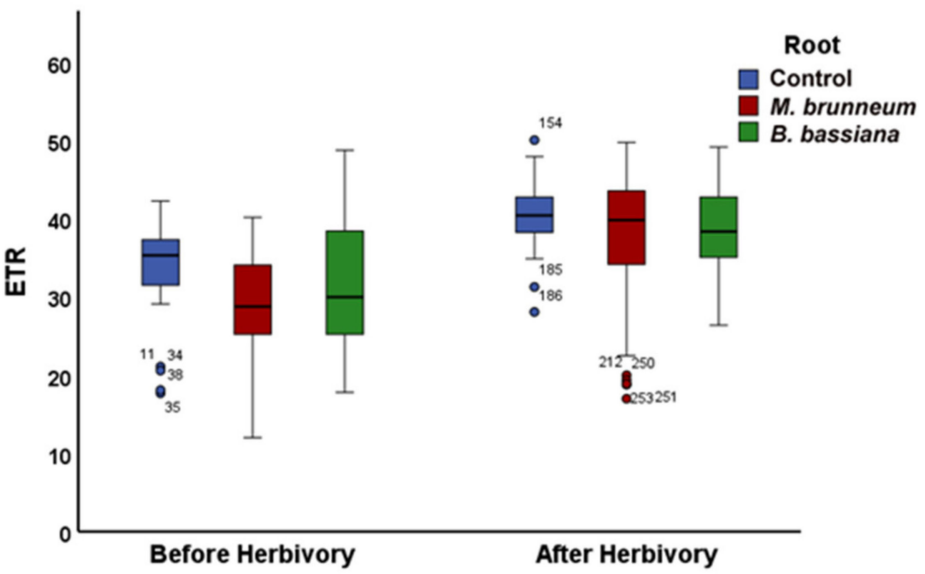

(b)

Figure 5. (a) Non-photochemical quenching (NPQ) and (b) electron transport rate (ETR) of tomato leaflets before and after insect feeding, shown for control plants (blue, untreated and treated combined) M. brunneum-inoculated (red), and B. bassiana-inoculated plants (green). Boxes and whiskers explained in Figure 1. For statistical significances, see Supplementary Table S4.

In B. bassiana-inoculated plants, the non-photochemical energy quenching (NPQ) was also higher than in control plants $(11 \%)$, which had no effect on the electron transport rate (ETR) (Figure 5a,b; Table S4). The fraction of open reaction centers $\left(\mathrm{q}_{P}\right)$ was $18 \%$ lower than in control plants; in accordance, the excess excitation energy (EXC) was $8 \%$ higher than in control plants (Figure 6a,b; Tables S3 and S5).

\subsubsection{After Herbivory}

In B. bassiana-inoculated plants, the non-photochemical energy quenching (NPQ) was $9 \%$ higher than in control plants and $9 \%$ higher than in M. brunneum-inoculated plants (Figures 5a and S1a; Table S4). The control, M. brunneum treatment, and B. bassiana treatment did not differ for electron transport rate (ETR) or excess excitation energy (EXC) after herbivory (Figures 5b, 6b, Figure S1b and S2b; Tables S4 and S5), but both M. brunneumand $B$. bassiana-inoculated plants had $7 \%$ less open reaction centers than control plants (Figures 6a and S2a; Table S3).

Plants inoculated with M. brunneum had a 22\% and 19\% lower NPQ and EXC after herbivory than before (Figures 5a, 6b, Figure S1a and S2b; Tables S4 and S5), respectively. 
Simultaneously, they upregulated their electron transport rate by $32 \%$ and had $27 \%$ more open reaction centers than before herbivory (Figures 5b, 6a, S1b and S2a; Tables S4 and S3).

B. bassiana-inoculated plants had 23\% and 16\% lower NPQ and EXC than before herbivory, respectively (Figures 5a, 6b, S1a and S2b; Tables S4 and S5); similar to the $M$. brunneum-inoculated plants, they increased ETR (Figures 5b and S1b; Table S4) and $\mathrm{q}_{P}$ (Figures $6 \mathrm{a}$ and S2a; Table S3) by $30 \%$ and $22 \%$ than before herbivory.

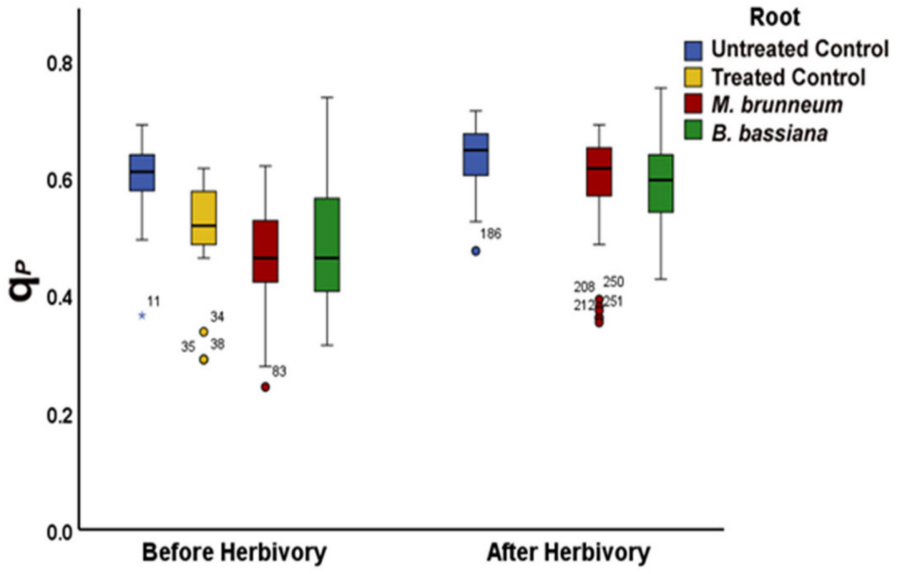

(a)

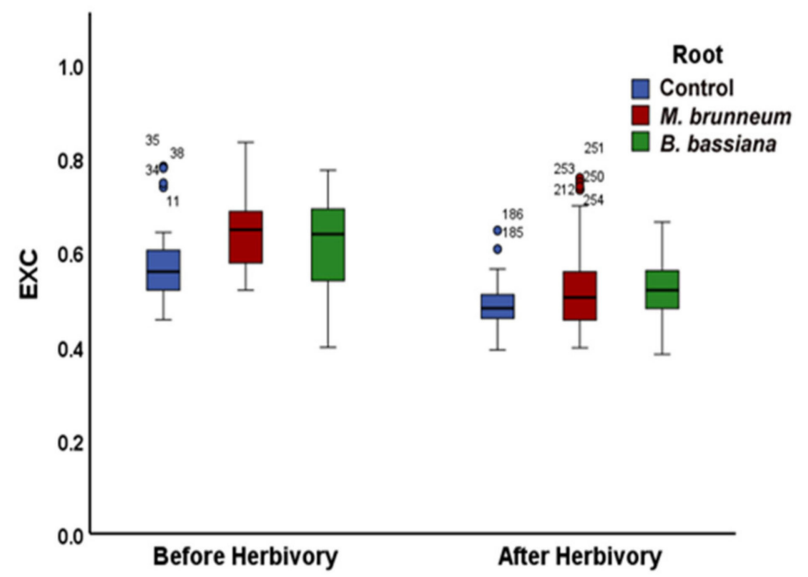

(b)

Figure 6. (a) Fraction of open PSII reaction centers $\left(\mathrm{q}_{p}\right)$ and (b) excess excitation energy (EXC) of tomato leaflets before and after insect feeding, shown for untreated and treated control plants (blue, yellow; or combined), M. brunneum-inoculated (red), and B. bassiana-inoculated plants (green). Boxes and whiskers explained in Figure 1. For statistical significances, see Supplementary Tables S3 ( $\left.\mathrm{q}_{p}\right)$ and S5 (EXC).

\subsection{Spatial Heterogeneity of Photosystem II Photochemistry in Response to Herbivory by Spodoptera exigua larvae}

In both M. brunneum- and B. bassiana-inoculated plants, the fraction of energy used for photochemistry $\left(\Phi_{P S I I}\right)$ was higher in leaf-zones surrounding the feeding spots and the rest of the leaflets than at the feeding spots (Figures 7a and 8; Table S6) similar to the control plants. However, $\Phi_{P S I I}$ of the rest of the leaflet of M. brunneum-inoculated plants was lower than the rest of the leaflet of control plants (Figures 7a and 8; Table S6). The feeding spots of $B$. bassiana-inoculated plants had significantly higher $\Phi_{P S I I}$ compared with the feeding spot of control plants.

Both M. brunneum- and B. bassiana-inoculated plants had higher fractions of regulated energy dissipated as heat $\left(\Phi_{N P Q}\right)$ in the zones surrounding the feeding spot as well as in the rest of the leaflet (Figures $7 \mathrm{~b}$ and 8; Table S6), same as the control plants. However, $\Phi_{N P Q}$ at the feeding spots of B. bassiana-inoculated plants was significantly higher than on M. brunneum-inoculated and control plants (Figures 7b and 8; Table S6).

Both M. brunneum- and B. bassiana-inoculated plants had lower non-regulated energy losses $\left(\Phi_{N O}\right)$ in the zones surrounding feeding spots and the rest of the leaflet than at the feeding spots (Figures 8 and 9; Table S7). $\Phi_{N O}$ was significantly lower at the feeding spots of both M. brunneum- and B. bassiana-inoculated plants than at the feeding spots of control plants (Figures 8 and 9; Table S7). In addition, $\Phi_{N O}$ at the feeding spots was significantly lower in B. bassiana- than M. brunneum-inoculated plants (Figures 8 and 9; Table S7). 


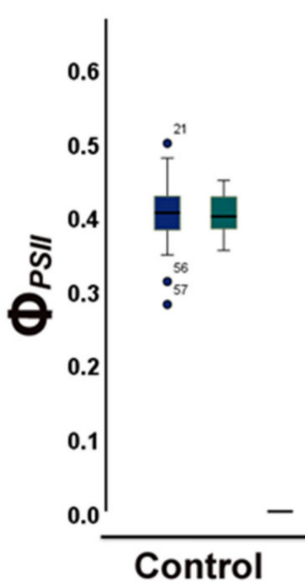

Control

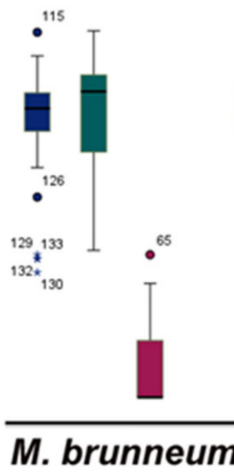

(a)

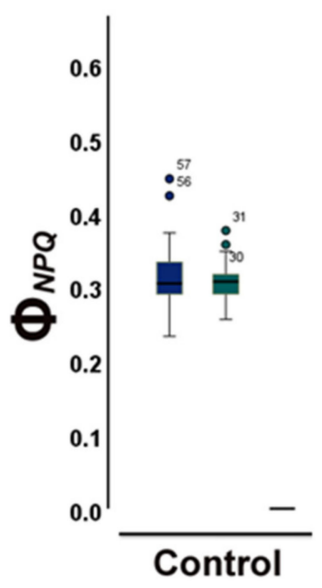

B. bassiana

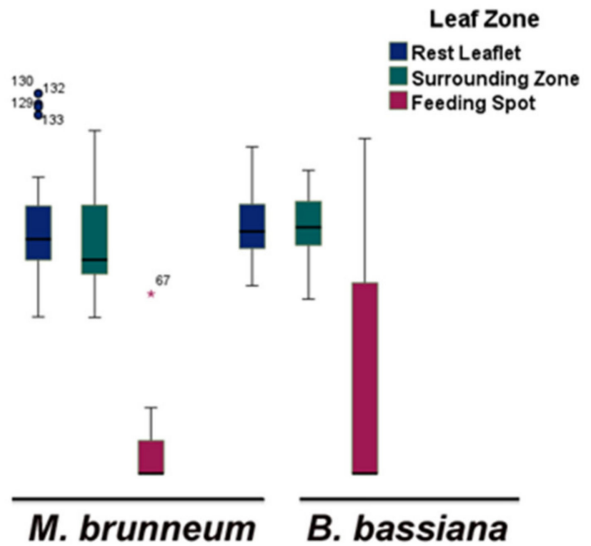

(b)

Figure 7. Fraction of absorbed light energy (a) used for photochemistry $\left(\Phi_{P S I I}\right)$ and (b) lost in regulated non-photochemical processes $\left(\Phi_{N P Q}\right)$, shown for three different leaflet zones: directly at feeding spots (red), in zones surrounding the feeding spot (green), and in the rest of the leaflet (blue), for control, M. brunneum-inoculated, and B. bassiana-inoculated plants. Boxes and whiskers explained in Figure 1. For statistical significances, see Supplementary Table S6.

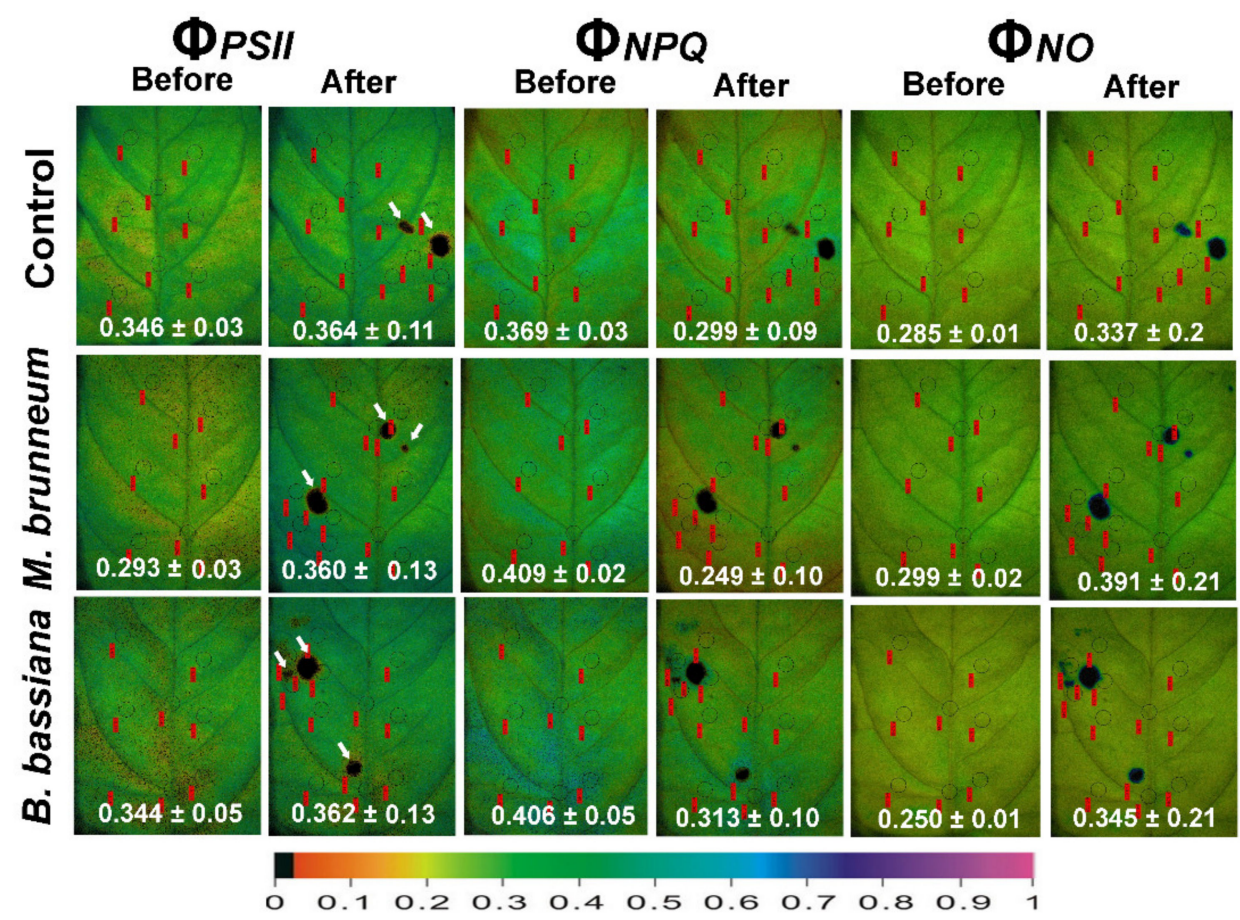

Figure 8. Representative color-coded images of the fraction of absorbed light energy, used for photochemistry $\left(\Phi_{P S I I}\right)$, dissipated as heat-regulated loss $\left(\Phi_{N P Q}\right)$, and nonregulated loss $\left(\Phi_{N O}\right)$ of tomato leaflets before and after insect feeding, for treated control plants, M. brunneum-inoculated, and B. bassiana-inoculated plants. Initial measurement areas (areas of interests, AOIs) are shown in circles with associated chlorophyll fluorescence values in red labels. After insect feeding, new AOIs were added to cover the feeding spots of herbivory (shown by white arrows). The whole leaflet's corresponding values (average \pm SD) are given in white. The color code at the bottom of the images ranges from pixel values 0.0 (black) to 1.0 (purple). 


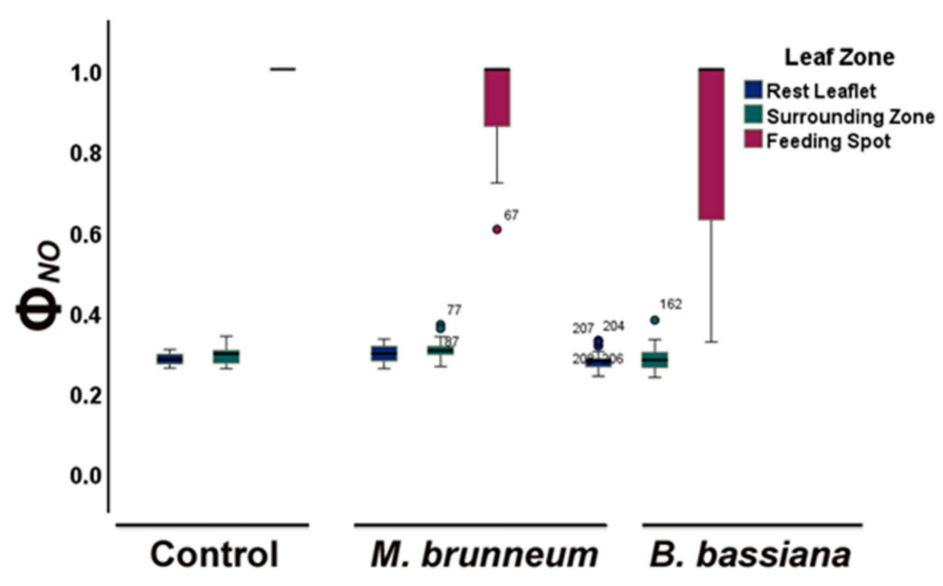

Figure 9. Fraction of absorbed light energy loss nonregulated $\left(\Phi_{N O}\right)$, shown for three different zones: directly at feeding spots (red), in zones surrounding the feeding spots (green), and in the rest of the leaflet (blue), for control, M. brunneum-inoculated, and B. bassiana-inoculated plants. Boxes and whiskers explained in Figure 1. For statistical significance, see Supplementary Table S7.

\section{Discussion}

Plant colonization by beneficial fungi can stimulate the plant's immune system, rendering the plant more resistant to herbivory by inducing systemic resistance, but the effect of beneficial fungi on plant relations with herbivorous insects is controversial [53-57], i.e., an efficient activation of the plant defense response upon pathogen or herbivory attacks [53]. For example, the leaf-chewer Spodoptera exigua had a higher mortality when feeding on tomato plants colonized by the mycorrhizal fungus Funneliformis mosseae, demonstrating mycorrhiza-induced resistance by accumulation of defense compounds [53].

However, the effects of associated fungi on plant relations with herbivorous insects are contradictory $[54,55,58]$ with contrasting results, e.g., the effects of mycorrhiza on aboveground attackers. This suggests that "beneficial" root-associated fungi can either increase, decrease, or have no effect on plant tolerance-associated mechanisms [58]. Contradicting results have also been reported on the effect of inoculation with B. bassiana and M. brunneum, two fungi that are otherwise known as entomopathogens but can also associate with plant roots. B. bassiana-inoculation has been shown to reduce consumption of soybean leaves by Helicoverpa gelotopoeon larvae [59] but increase fecundity of second-generation aphids (Aphis fabae) on Vicia faba plants [60]. Inoculation with M. brunneum on soybeans increased the populations of the aphid Aphis glycines while B. bassiana inoculations had no effect [61].

Plant-fungus associations may also affect photosynthesis, which is highly important both for plant defense against antagonists and for compensatory responses. Inoculation of Salvia fruticose with the mycorrhizal fungus Rhizophagus irregularis increased the fraction of light energy used for photosynthesis $\left(\Phi_{\text {PSII }}\right)$ and decreased the excess excitation energy (EXC) [33]. The effects of root-associated entomopathogenic fungi on the plant's photosynthesis have not been studied before, to our knowledge, but may help in understanding and solving the contradictory effects of these fungi on plant interactions with antagonists.

In our study, the fraction of light energy used for photochemistry $\left(\Phi_{P S I I}\right)$ before herbivory was lower in M. brunneum-inoculated plants than in control plants, while there was no difference to controls in B. bassiana-inoculated plants (Figure 1a; Table S2), contradicting the effect of mycorrhizal fungi on $\Phi_{\text {PSII. }}$. In both $M$. brunneum- and B. bassianainoculated plants, a higher fraction of energy was photoprotectively dissipated as heat $\left(\Phi_{N P Q}\right)$ than in control plants (Figure 1b; Table S2). However, this photoprotective mechanism was sufficient only in B. bassiana-inoculated plants and not in M. brunneum, in which an increase of the quantum yield of nonregulated loss in PSII $\left(\Phi_{\mathrm{NO}}\right)$ was observed (Figure 2; Table S3). $\Phi_{N O}$ comprises chlorophyll fluorescence internal conversions and intersystem crossing, resulting to singlet oxygen $\left({ }^{1} \mathrm{O}_{2}\right)$ formation through the triplet state of chlorophyll $\left({ }^{3} \mathrm{chl}^{*}\right)[27,33,62,63]$. The ${ }^{1} \mathrm{O}_{2}$ generated this way is a damaging reactive 
oxygen species (ROS) produced in PSII [64-67]. We can thus conclude that inoculation of tomato plants with M. brunneum may have a (slightly) negative impact on host plants under normal conditions, and that different entomopathogenic fungi differentially modulate PSII photochemistry. This is in accordance with literature reports, where different entomopathogenic fungi have different effects on plant and insect performance [68]. Even different Metarhizium species can affect photosynthesis differently [41,69,70].

After a short-term herbivory by chewing S. exigua larvae, the fraction of absorbed light energy used for photochemistry $\left(\Phi_{\text {PSII }}\right)$ increased in both $M$. brunneum- and B. bassiana-inoculated plants as well as in control plants (Figures 1a and 3a; Table S2). Simultaneously, the photoprotective heat dissipation $\left(\Phi_{N P Q}\right)$ decreased in all treatments (Figures $1 \mathrm{~b}$ and $3 \mathrm{~b}$; Table S2) compared with before herbivory. These decreases in $\Phi_{N P Q}$ resulted an increase in the nonregulated energy loss $\left(\Phi_{N O}\right)$ in M. brunneum- but not in B. bassiana-inoculated plants (Figures 2 and 4; Table S3). This was due to a higher nonphotochemical quenching in B. bassiana-inoculated plants compared with control. Nonphotochemical quenching (NPQ) can dissipate the excess light energy as heat, acting as a photoprotective mechanism of photosynthesis [71-73], regulating the energy that might lead to the creation of singlet oxygen $\left({ }^{1} \mathrm{O}_{2}\right)$. Spodoptera exigua larvae feeding on both M. brunneum- and B. bassiana-inoculated plants activated a compensatory PSII response mechanism that, by downregulating the systemic signaling of NPQ, upregulated their electron transport rate (ETR) (Figure 5a,b; Table S4). Defense response mechanisms can be triggered by NPQ so that light energy allocation is adjusted in order to have an enhanced PSII functionality [31]. Together, this suggests that tomato leaflets initiate a compensatory mechanism that increases their photosynthetic efficiency in response to herbivore feeding, but this is not substantially different between inoculated and noninoculated plants. In addition, despite the initial negative effect on photosynthesis by M. brunneum, the plants manage to activate the same compensatory mechanism as control plants to reach the same photosynthetic efficiency $\left(\Phi_{\text {PSII }}\right)$ as control plants. In addition, B. bassiana-inoculated plants had higher photoprotection (higher NPQ, Figure 5a; Table S4) and lower formation of singlet oxygen $\left({ }^{1} \mathrm{O}_{2}\right)$.

In our spatial analyses, in both fungal treatments and control plants, the leaf zone surrounding the larval feeding spots and the remaining leaflet area had higher $\Phi_{P S I I}$ than before herbivory but also compared with the feeding spot. Both fungal treatments had higher $\Phi_{N P Q}$ in their surrounding zone and the rest of the leaflet than the feeding spot. However, the $\Phi_{N P Q}$ in the feeding spot of B. bassiana-inoculated plants was significantly higher compared with the M. brunneum-inoculated and control plants. Lastly, the feeding spot, as expected, had the highest $\Phi_{N O}$ compared with the rest of the leaflet and the surrounding zone in both treatments. Nevertheless, the $\Phi_{N O}$ of the feeding spot of B. bassiana-inoculated plants was significantly lower than that of M. brunneum-inoculated plants as well as control plants. During our experiments, we also observed that the individual S. exigua larvae tended to feed on more leaf spots within the tested leaflet of B. bassiana-inoculated plants but caused lower damage on each leaf spot (J. Moustaka pers. obs). This may explain the differences in the feeding spots of B. bassiana-inoculated plants in their $\Phi_{N P Q}$ and $\Phi_{N O}$. Inoculation with $B$. bassiana has previously been found to enhance the levels of terpenoids on tomato plants, which resulted in reduced weight gain in S. exigua larvae feeding on the plants [50].

The compensatory reaction to herbivory can minimize a reduction in growth or reproduction of the plant after herbivore attack, improving fitness of plants growing in environments with a high herbivory level [74]. The compensatory capability differs, varying with the plant species, the extent of the leaf area lost, the timing of the herbivory, the environmental conditions, and the mode of herbivore injury [44,74]. Such a compensatory is rationalized by a higher requirement of the remaining leaf area for a higher fraction of the absorbed light energy for photochemistry to fix larger amounts of carbon [44,74]. The light reactions of photosynthesis feed the energy supply required for the production of compounds used in defense, such as hormones, and other defense-related metabolites [26,75]. 
Overall, our results suggest that before herbivory, $M$. brunneum had a negative effect on the photosynthetic efficiency of the tomato plants, whereas B. bassiana did not. After herbivory, both the inoculated and noninoculated plants upregulated their photosynthetic efficiency, both at the whole leaflet level but also locally in the zone surrounding the feeding spot. The ability of M. brunneum-inoculated plants to increase their photosynthetic efficiency after herbivory to the same level as control plants, despite their initial (before herbivory) negative effect, suggests a higher defense response. Associations with both entomopathogenic fungi, and especially B. bassiana, seemed to diminish the negative effects of herbivory on photosynthetic efficiency locally in the feeding spots. This suggests that B. bassiana-inoculated plant had an improved response to herbivory since these plants increased their photosynthetic efficiency, showing the activation of the same compensatory mechanism as noninoculated plants, but they also managed to regulate their excess energy by increasing their $\Phi_{N P Q}$ instead of increasing the harmful nonregulated energy loss, $\Phi_{N O}$. We can conclude that inoculation of tomato plants with different entomopathogenic fungi differentially modulates PSII photochemistry.

\section{Materials and Methods}

\subsection{Plant Material and Growth Conditions}

Surface sterilized seeds ( 1 min in $70 \%$ ethanol followed by $10 \mathrm{~min}$ in $1 \%$ sodium hypochlorite, followed by 6 washes with sterilized water) of tomato plants (Solanum lycopersicum cv. Moneymaker; Kings seeds, Essex UK) were sown in 2 lt pots with potting soil (clay and silica; SW Horto AB, Hammenhög, Sweden). Plants were grown in a greenhouse for 5 weeks at $19 \pm 1 / 17 \pm 1{ }^{\circ} \mathrm{C}$ day/night temperature, with a photoperiod of 16-h day at $180 \pm 20 \mu \mathrm{mol}$ photons $\mathrm{m}^{-2} \mathrm{~s}^{-1}$ light, and $60 \pm 5 \%$ relative humidity. Six-week-old plants were used for the experiments.

\subsection{Spodoptera exigua}

Spodoptera exigua larvae were cultured from eggs (Entocare Wageningen, Netherlands) on an artificial diet [44] prior to experiments and kept under controlled conditions at $21 \pm 1{ }^{\circ} \mathrm{C}$ day/night temperature, with a 12-h light cycle and $38 \pm 5 \%$ relative humidity. The larvae used in the experiments were L2 instar larvae, which were starved for $24 \mathrm{~h}$ before exposing them to the tomato leaflets, assuring a faster consumption.

\subsection{Fungal Isolates and Suspensions}

Two different root-associated entomopathogenic fungi were obtained from the collection of University of Copenhagen: Metarhizium brunneum KVL 16-36, which is isolated from the commercial product Met52 ${ }^{\circledR}$; Beauveria bassiana KVL 13-39, which is isolated from the commercial product BotaniGard ${ }^{\circledR}$. We chose to work with $B$. bassiana as it has already been broadly studied as a potential plant-associated entomopathogenic fungi with the ability to affect feeding of herbivorous insects and mites $[3,55,68,76,77]$. The species M. brunneum is less characterized for its effects on herbivory, but recently, has been shown to induce resistance against pests and pathogens [78]. Furthermore, isolate KVL 16-36 has been shown to alter the plant phenotype [79]. Both fungal isolates are obtained from commercial biocontrol products, which make them available for use in plant production systems in several countries. The fungal cultures were propagated in Saboraud Dextrose Agar plates (SDA) at $23^{\circ} \mathrm{C}$ and darkness for 14-20 days. Fungal suspensions were prepared by adding $10 \mathrm{~mL}$ of Triton $\mathrm{X} 0.05 \%$ to the surface of the plates and scraping spores off with sterile glass spatula. The suspensions were filtered through sterile cheesecloth to remove the hyphal fragments and agar bits, centrifuged for $3 \mathrm{~min}$ at $3000 \times g \mathrm{rpm}$, and the supernatant was discarded. The precipitated spores were resuspended in $10 \mathrm{~mL}$ of Triton $X 0.05 \%$. The spore concentration was estimated by counting in a Fuchs-Rosenthal hemocytometer (Assistant, Sondheim von der Rhön, Germany, $0.0625 \mathrm{~mm}^{2}$, depth $0.200 \mathrm{~mm}$ ) and adjusted to a final concentration of $1 \times 10^{8}$ spores $\mathrm{mL}^{-1}$. The spore germination of the suspensions was tested by spreading a diluted sample $\left(100 \mu \mathrm{L}\right.$ of $\left.1 \times 10^{4}\right)$ on two SDA plates, after $24 \mathrm{~h}$ culturing, 
counting germinated and nongerminated spores. Suspensions with a germination rate of at least $90 \%$ were used for the experiment.

\subsection{Experimental Design}

Our experiment included four experimental plant treatments: untreated control, treated control, Beauveria bassiana inoculation, and Metarhizium brunneum inoculation, each with 6 replicates. On the sowing day, $1 \mathrm{ml}$ of either tap water (Untreated Control), Triton X $0.05 \%$ (Treated Control), $1 \times 10^{8} \mathrm{~mL}^{-1}$ spores of Beauveria bassiana, or Metarhizium brunneum was added to the surrounding of each seed. In each of the experimental plants, the terminal leaflet of the 4 th leaf was used for the experimental measurements, as previously described [44]. Photosynthetic efficiency was measured before herbivory (Before) and immediately after a 15-min short feeding period by S. exigua (After). Subsequently, the roots of the plants were cleaned with tap water and a subsample containing primary and lateral roots was collected for assessment of fungal colonization, using a protocol modified from Steinwender et al. (2015) [80]. Briefly, roots were cut in 1-cm pieces and mixed to homogenize, after 20 pieces were selected randomly, added to a 15-mL glass tube containing $5 \mathrm{~mL}$ of sterile Triton $X(0.05 \%)$ and homogenized with a rotating pestle. A $100 \mu \mathrm{L}$ suspension was spread in selective media containing Streptomycin $0.5 \mathrm{~mL}$ of $0.6 \mathrm{~g} / \mathrm{mL}$, Tetracycline $0.5 \mathrm{~mL}$ of $0.05 \mathrm{~g} / \mathrm{mL}$, Cycloheximide $1 \mathrm{~mL}$ of $0.05 \mathrm{~g} / \mathrm{mL}$, and dodine $0.2 \mathrm{~mL}$ of $0.1 \mathrm{~g} / \mathrm{mL}$ and incubated at $23{ }^{\circ} \mathrm{C}$ in darkness for 2 weeks. Colony Forming Units (CFU) that had the morphological units of the inoculated isolates were quantified on the 14th day for each plant (data not shown).

\subsection{Chlorophyll Fluorescence Imaging Analysis}

Chlorophyll $a$ fluorescence was measured at room temperature using an imaging-PAM fluorometer (Walz, Effeltrich, Germany), as described previously [44]. Each leaflet was adapted in darkness for 15 min prior to measurement ensuring that all reaction centers were opened. Ten Areas of Interest (AOI) were added in each leaflet before herbivory and new AOIs were added after herbivory with one AOI in each feeding spot and two AOIs in the surrounding area of each feeding spot. Whenever a feeding spot was close to or inside an existing AOI (from the before measurement), it was considered as being in the surrounding AOI or the feeding spot in our analyses. For each AOI, we firstly measured and determined the minimum and the maximum chlorophyll $a$ fluorescence in the dark (Fo and Fm, respectively). Steady-state photosynthesis (Fs) was measured after $5 \mathrm{~min}$ of illumination time with Actinic Light (AL) of $200 \mu \mathrm{mol}$ photons $\mathrm{m}^{-2} \mathrm{~s}^{-1}$ in accordance with the growth light conditions of the plants. Maximum chlorophyll $a$ fluorescence in the light $\left(\mathrm{Fm}^{\prime}\right)$ was measured with saturating pulses (SPs) every $20 \mathrm{~s}$ for 5 min after application of the AL. The minimum chlorophyll $a$ fluorescence in the light $\left(\mathrm{Fo}^{\prime}\right)$ was computed as $\mathrm{Fo}^{\prime}=\mathrm{Fo} /\left(\mathrm{Fv} / \mathrm{Fm}+\mathrm{Fo} / \mathrm{Fm}^{\prime}\right)$ [81] by the Imaging Win software. The variable chlorophyll $a$ fluorescence $(\mathrm{Fv})$ in the dark-adapted leaves was calculated as $\mathrm{Fm}$-Fo. The measured chlorophyll fluorescence parameters are shown in Table 1. Values were estimated as averages from six separate measurements.

Table 1. Definitions of the measured chlorophyll fluorescence parameters.

\begin{tabular}{|c|c|c|}
\hline Parameter & Definition & Calculation \\
\hline$\Phi_{P S I I}$ & Effective quantum yield of PSII photochemistry & $\left(\mathrm{F} m^{\prime}-\mathrm{Fs}\right) / \mathrm{F} m^{\prime}[52]$ \\
\hline$\Phi_{N P Q}$ & Quantum yield of regulated non-photochemical energy loss in PSII & $\mathrm{FS}_{S} / \mathrm{Fm}^{\prime}-\mathrm{FS} / \mathrm{Fm}[52]$ \\
\hline$\Phi_{N O}$ & Quantum yield of nonregulated loss in PSII & Fs $/ \mathrm{F} m[52]$ \\
\hline NPQ & $\begin{array}{l}\text { Non-photochemical quenching reflecting the dissipation of } \\
\text { excitation energy as heat }\end{array}$ & $\left(\mathrm{F} m-\mathrm{F} m^{\prime}\right) / \mathrm{Fm}^{\prime}[82]$ \\
\hline ETR & Electron transport rate & $\begin{array}{l}\Phi_{\mathrm{PSII}} \times \text { PAR } \times \mathrm{c} \times \text { abs, where PAR is the photosynthetically active radiation, } \\
\quad \mathrm{c} \text { is } 0.5 \text {, and abs is the total light absorption of the leaf taken as } 0.84 \text { [83] }\end{array}$ \\
\hline $\mathrm{q}_{p}$ & $\begin{array}{l}\text { Photochemical quenching, representing the fraction of open PSII } \\
\text { reaction centers }\end{array}$ & $\left(\mathrm{F} m^{\prime}-\mathrm{Fs}\right) /\left(\mathrm{F} m^{\prime}-\mathrm{Fo}^{\prime}\right)[84]$ \\
\hline EXC & Excess excitation energy & $\left(\mathrm{Fv} / \mathrm{F} m-\Phi_{\mathrm{PSII}}\right) / \mathrm{Fv} / \mathrm{F} m[85]$ \\
\hline
\end{tabular}


The spatiotemporal response of the leaflets is displayed with representative colorcoded images in Figure 8 obtained with $200 \mu \mathrm{mol}$ photons $\mathrm{m}^{-2} \mathrm{~s}^{-1}$ AL.

\subsection{Statistical Analysis}

The results of the chlorophyll fluorescence analysis were split into (a) the whole leaflet response before herbivory as a mean value of all the AOIs per treatment, (b) the whole leaflet response after herbivory as a mean value of all the AOIs per treatment, and (c) as the response in three zones-feeding spots, surrounding zones, and rest of the leaflet area.

First, we compared the untreated and treated control treatments to evaluate if they were significantly different or could be combined. This was tested with a two-way (Herbivory and Root treatment) repeated measures ANOVA. Comparing the two controls before herbivory as well as after herbivory allowed us to determine in which measurements we could combine the two control treatments. Next, we tested if the fungi-inoculated plants had a different photosynthetic response before and after herbivory at the whole leaflet level. We tested this for all the photosynthetic parameters measured using a two-way repeated measures ANOVA with Root Treatment and Herbivory as the two factors, with post hoc comparisons using Dunn-Šidák correction. Finally, we analyzed whether the photosynthetic response to herbivory was different between leaf zones-feeding spot, surrounding area, or rest of the leaflet area-using a two-way ANOVA of the effect of Area and Root treatment on all measurements. Variance of homogeneity was verified with Levene's test and the normality using Shapiro-Wilk test. Significance was estimated at a level of $p<0.05$. Data analysis and graphs were obtained using IBM SPSS Statistics for Windows version 28.0.

Supplementary Materials: Table S1: Comparison of controls, Table S2: Percentage pairwise differences between experimental treatments for $\Phi_{P S I I}$ and $\Phi_{N P Q}$, Table S3: Percentage pairwise differences between experimental treatments for $\Phi_{N O}$, Table S4: Percentage pairwise differences between experimental treatments for NPQ and ETR, Table S5: Percentage pairwise differences between experimental treatments for $\mathrm{q}_{P}$ and EXC, Table S6: Statistical significance of pairwise differences between different leaflet zones for $\Phi_{P S I I}$ and $\Phi_{N P Q}$ Table S7: Statistical significance of pairwise differences between different leaflet zones for $\Phi_{N O}$, Figure S1: Graphs showing percentage changes in NPQ and ETR between treatments, Figure S2: Graphs showing percentage changes in $\mathrm{q}_{P}$ and EXC.

Author Contributions: Conceptualization, T.P.H. and J.M.; methodology, J.M.; formal analysis, J.M.; investigation, J.M.; resources, T.P.H.; data curation, J.M.; writing-original draft preparation, J.M.; writing-review and editing, T.P.H. and N.V.M.; supervision, T.P.H. and N.V.M.; project administration, T.P.H.; funding acquisition, T.P.H. All authors have read and agreed to the published version of the manuscript.

Funding: This research was funded by the European Union's Horizon 2020 research and Innovation programme, Microbe Induced Resistance to Agricultural Pests (MiRA), Grant agreement No 765290.

Institutional Review Board Statement: Not applicable.

Informed Consent Statement: Not applicable.

Data Availability Statement: The data presented in this study are available in this article.

Acknowledgments: The authors would like to thank Michael Moustakas (Department of Botany, Aristotle University of Thessaloniki) for providing the Chlorophyll Fluorometer used in this study.

Conflicts of Interest: The authors declare no conflict of interest. The funders had no role in the design of the study; in the collection, analyses, or interpretation of data; in the writing of the manuscript, or in the decision to publish the results.

Sample Availability: Not applicable.

\section{References}

1. Fraser, E.D.G. The challenge of feeding a diverse and growing population. Physiol. Behav. 2020, 221, 112908. [CrossRef] [PubMed]

2. Struik, P.C.; Kuyper, T.W. Sustainable intensification in agriculture: The richer shade of green. A review. Agron. Sustain. Dev. 2017, 37, 39. [CrossRef] 
3. Sinno, M.; Ranesi, M.; Di Lelio, I.; Iacomino, G.; Becchimanzi, A.; Barra, E.; Molisso, D.; Pennacchio, F.; Digilio, M.C.; Vitale, S.; et al. Selection of Endophytic Beauveria bassiana as a Dual Biocontrol Agent of Tomato Pathogens and Pests. Pathogens 2021, $10,1242$. [CrossRef]

4. Finkel, O.M.; Castrillo, G.; Paredes, S.H.; Gonzalez, I.S.; Dangl, J.L. Understanding and exploiting plant beneficial microbes. Curr. Opin. Plant Biol. 2017, 38, 155-163. [CrossRef]

5. Vega, F.E.; Goettel, M.S.; Blackwell, M.; Chandler, D.; Jackson, M.A.; Keller, S.; Koike, M.; Maniania, N.K.; Monzón, A.; Ownley, B.H.; et al. Fungal entomopathogens: New insights on their ecology. Fungal Ecol. 2009, 2, 149-159. [CrossRef]

6. Mantzoukas, S.; Eliopoulos, P.A. Endophytic Entomopathogenic Fungi: A Valuable Biological Control Tool against Plant Pests. Appl. Sci. 2020, 10, 360. [CrossRef]

7. Chandler, D. Basic and Applied Research on Entomopathogenic Fungi. In Microbial Control of Insect and Mite Pests; Elsevier: Amsterdam, The Netherlands, 2017; pp. 69-89.

8. Lacey, L.A.; Grzywacz, D.; Shapiro-Ilan, D.I.; Frutos, R.; Brownbridge, M.; Goettel, M.S. Insect pathogens as biological control agents: Back to the future. J. Invertebr. Pathol. 2015, 132, 1-41. [CrossRef]

9. Litwin, A.; Nowak, M.; Różalska, S. Entomopathogenic fungi: Unconventional applications. Rev. Environ. Sci. Biotechnol. 2020, 19, 23-42. [CrossRef]

10. Jaber, L.R.; Ownley, B.H. Can we use entomopathogenic fungi as endophytes for dual biological control of insect pests and plant pathogens? Biol. Control 2018, 116, 36-45. [CrossRef]

11. Barelli, L.; Moonjely, S.; Behie, S.W.; Bidochka, M.J. Fungi with multifunctional lifestyles: Endophytic insect pathogenic fungi. Plant Mol. Biol. 2016, 90, 657-664. [CrossRef] [PubMed]

12. Behie, S.W.; Jones, S.J.; Bidochka, M.J. Plant tissue localization of the endophytic insect pathogenic fungi Metarhizium and Beauveria. Fungal Ecol. 2015, 13, 112-119. [CrossRef]

13. Tall, S.; Meyling, N.V. Probiotics for Plants? Growth Promotion by the Entomopathogenic Fungus Beauveria bassiana Depends on Nutrient Availability. Microb. Ecol. 2018, 76, 1002-1008. [CrossRef] [PubMed]

14. Canassa, F.; D'Alessandro, C.P.; Sousa, S.B.; Demétrio, C.G.; Meyling, N.V.; Klingen, I.; Delalibera, I. Fungal isolate and crop cultivar influence the beneficial effects of root inoculation with entomopathogenic fungi in strawberry. Pest Manag. Sci. 2020, 76, 1472-1482. [CrossRef]

15. Rasool, S.; Vidkjær, N.H.; Hooshmand, K.; Jensen, B.; Fomsgaard, I.S.; Meyling, N.V. Seed inoculations with entomopathogenic fungi affect aphid populations coinciding with modulation of plant secondary metabolite profiles across plant families. New Phytol. 2021, 229, 1715-1727. [CrossRef] [PubMed]

16. Akutse, K.S.; Maniania, N.K.; Fiaboe, K.K.M.; Van den Berg, J.; Ekesi, S. Endophytic colonization of Vicia faba and Phaseolus vulgaris (Fabaceae) by fungal pathogens and their effects on the life-history parameters of Liriomyza huidobrensis (Diptera: Agromyzidae). Fungal Ecol. 2013, 6, 293-301. [CrossRef]

17. Powell, W.A.; Klingeman, W.E.; Ownley, B.H.; Gwinn, K.D. Evidence of Endophytic Beauveria bassiana in Seed-treated Tomato Plants Acting as a Systemic Entomopathogen to Larval Helicoverpa zea (Lepidoptera: Noctuidae). J. Entomol. Sci. 2009, 44, 391-396. [CrossRef]

18. Dash, C.K.; Bamisile, B.S.; Keppanan, R.; Qasim, M.; Lin, Y.W.; Ul Islam, S.; Hussain, M.; Wang, L.D. Endophytic entomopathogenic fungi enhance the growth of Phaseolus vulgaris L. (Fabaceae) and negatively affect the development and reproduction of Tetranychus urticae Koch (Acari: Tetranychidae). Microb. Pathog. 2018, 125, 385-392. [CrossRef]

19. Klieber, J.; Reineke, A. The entomopathogen Beauveria bassiana has epiphytic and endophytic activity against the tomato leaf miner Tuta absoluta. J. Appl. Entomol. 2016, 140, 580-589. [CrossRef]

20. Ownley, B.H.; Gwinn, K.D.; Vega, F.E. Endophytic fungal entomopathogens with activity against plant pathogens: Ecology and evolution. BioControl 2010, 55, 113-128. [CrossRef]

21. Behie, S.W.; Bidochka, M.J. Ubiquity of insect-derived nitrogen transfer to plants by endophytic insect-pathogenic fungi: An additional branch of the soil nitrogen cycle. Appl. Environ. Microbiol. 2014, 80, 1553-1560. [CrossRef]

22. Behie, S.W.; Zelisko, P.M.; Bidochka, M.J. Endophytic insect-parasitic fungi translocate nitrogen directly from insects to plants. Science 2012, 336, 1576-1577. [CrossRef] [PubMed]

23. Behie, S.W.; Moreira, C.C.; Sementchoukova, I.; Barelli, L.; Zelisko, P.M.; Bidochka, M.J. Carbon translocation from a plant to an insect-pathogenic endophytic fungus. Nat. Commun. 2017, 8, 14245. [CrossRef] [PubMed]

24. Huot, B.; Yao, J.; Montgomery, B.L.; He, S.Y. Growth-Defense Tradeoffs in Plants: A Balancing Act to Optimize Fitness. Mol. Plant 2014, 7, 1267-1287. [CrossRef]

25. Zhang, X.; Fu, J.; Hiromasa, Y.; Pan, H.; Bai, G. Differentially Expressed Proteins Associated with Fusarium Head Blight Resistance in Wheat. PLoS ONE 2013, 8, e82079. [CrossRef] [PubMed]

26. Sperdouli, I.; Moustaka, J.; Ouzounidou, G.; Moustakas, M. Leaf Age-Dependent Photosystem II Photochemistry and Oxidative Stress Responses to Drought Stress in Arabidopsis thaliana Are Modulated by Flavonoid Accumulation. Molecules 2021, $26,4157$. [CrossRef]

27. Muller, P.; Li, X.P.; Niyogi, K.K. Non-photochemical quenching. A response to excess light energy. Plant Physiol. 2001, 125, 1558-1566. [CrossRef]

28. Ruban, A.V. Nonphotochemical Chlorophyll Fluorescence Quenching: Mechanism and Effectiveness in Protecting Plants from Photodamage. Plant Physiol. 2016, 170, 1903-1916. [CrossRef] [PubMed] 
29. Hasanuzzaman, M.; Bhuyan, M.H.M.B.; Zulfiqar, F.; Raza, A.; Mohsin, S.M.; Mahmud, J.A.; Fujita, M.; Fotopoulos, V. Reactive Oxygen Species and Antioxidant Defense in Plants under Abiotic Stress: Revisiting the Crucial Role of a Universal Defense Regulator. Antioxidants 2020, 9, 681. [CrossRef] [PubMed]

30. Agathokleous, E.; Kitao, M.; Harayama, H. On the Nonmonotonic, Hormetic Photoprotective Response of Plants to Stress. Dose-Response 2019, 17, 1-3. [CrossRef]

31. Stamelou, M.-L.; Sperdouli, I.; Pyrri, I.; Adamakis, I.-D.S.; Moustakas, M. Hormetic Responses of Photosystem II in Tomato to Botrytis cinerea. Plants 2021, 10, 521. [CrossRef]

32. Foyer, C.H.; Noctor, G. Redox regulation in photosynthetic organisms: Signaling, acclimation, and practical implications. Antioxid. Redox Signal. 2009, 11, 861-905. [CrossRef] [PubMed]

33. Moustakas, M.; Baycu, G.; Sperdouli, I.; Eroglu, H.; Eleftheriou, E.P. Arbuscular Mycorrhizal Symbiosis Enhances Photosynthesis in the Medicinal Herb Salvia fruticosa by Improving Photosystem II Photochemistry. Plants 2020, 9, 962. [CrossRef]

34. Wu, Q.S.; Xia, R.X. Arbuscular mycorrhizal fungi influence growth, osmotic adjustment and photosynthesis of citrus under well-watered and water stress conditions. J. Plant Physiol. 2006, 163, 417-425. [CrossRef]

35. Birhane, E.; Sterck, F.J.; Fetene, M.; Bongers, F.; Kuyper, T.W. Arbuscular mycorrhizal fungi enhance photosynthesis, water use efficiency, and growth of frankincense seedlings under pulsed water availability conditions. Oecologia 2012, 169, 895-904 [CrossRef] [PubMed]

36. Chen, S.; Zhao, H.; Zou, C.; Li, Y.; Chen, Y.; Wang, Z.; Jiang, Y.; Liu, A.; Zhao, P.; Wang, M.; et al. Combined Inoculation with Multiple Arbuscular Mycorrhizal Fungi Improves Growth, Nutrient Uptake and Photosynthesis in Cucumber Seedlings. Front. Microbiol. 2017, 8, 2516. [CrossRef] [PubMed]

37. Liu, T.; Sheng, M.; Wang, C.Y.; Chen, H.; Li, Z.; Tang, M. Impact of arbuscular mycorrhizal fungi on the growth, water status, and photosynthesis of hybrid poplar under drought stress and recovery. Photosynthetica 2015, 53, 250-258. [CrossRef]

38. Sheng, M.; Tang, M.; Chen, H.; Yang, B.; Zhang, F.; Huang, Y. Influence of arbuscular mycorrhizae on photosynthesis and water status of maize plants under salt stress. Mycorrhiza 2008, 18, 287-296. [CrossRef]

39. He, L.; Li, C.; Liu, R. Indirect interactions between arbuscular mycorrhizal fungi and Spodoptera exigua alter photosynthesis and plant endogenous hormones. Mycorrhiza 2017, 27, 525-535. [CrossRef]

40. González-Guzmán, A.; Sacristán, D.; Sánchez-Rodríguez, A.R.; Barrón, V.; Torrent, J.; Del Campillo, M.C. Soil Nutrients Effects on the Performance of Durum Wheat Inoculated with Entomopathogenic Fungi. Agronomy 2020, 10, 589. [CrossRef]

41. Raya-Díaz, S.; Quesada-Moraga, E.; Barrón, V.; Del Campillo, M.C.; Sánchez-Rodríguez, A.R. Redefining the dose of the entomopathogenic fungus Metarhizium brunneum (Ascomycota, Hypocreales) to increase Fe bioavailability and promote plant growth in calcareous and sandy soils. Plant Soil 2017, 418, 387-404. [CrossRef]

42. Gómez-Vidal, S.; Salinas, J.; Tena, M.; Lopez-Llorca, L.V. Proteomic analysis of date palm (Phoenix dactylifera L.) responses to endophytic colonization by entomopathogenic fungi. Electrophoresis 2009, 30, 2996-3005. [CrossRef]

43. Krell, V.; Unger, S.; Jakobs-Schoenwandt, D.; Patel, A.V. Endophytic Metarhizium brunneum mitigates nutrient deficits in potato and improves plant productivity and vitality. Fungal Ecol. 2018, 34, 43-49. [CrossRef]

44. Moustaka, J.; Meyling, N.V.; Hauser, T.P. Induction of a Compensatory Photosynthetic Response Mechanism in Tomato Leaves upon Short Time Feeding by the Chewing Insect Spodoptera exigua. Insects 2021, 12, 562. [CrossRef] [PubMed]

45. Singh, V.K.; Singh, A.K.; Kumar, A. Disease management of tomato through PGPB: Current trends and future perspective. 3 Biotech 2017, 7, 255. [CrossRef] [PubMed]

46. Sinno, M.; Ranesi, M.; Gioia, L.; D’Errico, G.; Woo, S.L. Endophytic Fungi of Tomato and Their Potential Applications for Crop Improvement. Agriculture 2020, 10, 587. [CrossRef]

47. Shenge, K.C.; Mabagala, R.B.; Mortensen, C.N.; Stephan, D.; Wydra, K. First report of bacterial speck of tomato caused by Pseudomonas syringae pv. tomato in Tanzania. Plant Dis. 2007, 91, 462. [CrossRef]

48. Zhang, Z.C.; He, B.; Sun, S.; Zhang, X.; Li, T.; Wang, H.H.; Xu, L.R.; Afzal, A.J.; Geng, X.Q. The phytotoxin COR induces transcriptional reprogramming of photosynthetic, hormonal and defence networks in tomato. Plant Biol. 2021, $23,69-79$. [CrossRef] [PubMed]

49. Brewer, M.J.; Trumble, J.T.; Alvarado-Rodriguez, B.; Chaney, W.E. Beet Armyworm (Lepidoptera: Noctuidae) Adult and Larval Susceptibility to Three Insecticides in Managed Habitats and Relationship to Laboratory Selection for Resistance. J. Econ. Entomol. 1990, 83, 2136-2146. [CrossRef]

50. Shrivastava, G.; Ownley, B.H.; Augé, R.M.; Toler, H.; Dee, M.; Vu, A.; Köllner, T.G.; Chen, F. Colonization by arbuscular mycorrhizal and endophytic fungi enhanced terpene production in tomato plants and their defense against a herbivorous insect. Symbiosis 2015, 65, 65-74. [CrossRef]

51. Zheng, X.L.; Cong, X.P.; Wang, X.P.; Lei, C.L. A Review of Geographic Distribution, Overwintering and Migration in Spodoptera exigua Hubner (Lepidoptera: Noctuidae). J. Entomol. Res. Soc. 2011, 13, 39-48.

52. Kramer, D.M.; Johnson, G.; Kiirats, O.; Edwards, G.E. New Fluorescence Parameters for the Determination of QA Redox State and Excitation Energy Fluxes. Photosynth. Res. 2004, 79, 209-218. [CrossRef]

53. Rivero, J.; Lidoy, J.; Llopis-Giménez, Á.; Herrero, S.; Flors, V.; Pozo, M.J. Mycorrhizal symbiosis primes the accumulation of antiherbivore compounds and enhances herbivore mortality in tomato. J. Exp. Bot. 2021, 72, 5038-5050. [CrossRef] [PubMed]

54. Vega. The use of fungal entomopathogens as endophytes in biological control: A review. Mycologia 2018, 110, 4-30. [CrossRef] [PubMed] 
55. McKinnon, A.C.; Saari, S.; Moran-Diez, M.E.; Meyling, N.V.; Raad, M.; Glare, T.R. Beauveria bassiana as an endophyte: A critical review on associated methodology and biocontrol potential. BioControl 2017, 62, 1-17. [CrossRef]

56. Choudhary, D.K.; Prakash, A.; Johri, B.N. Induced systemic resistance (ISR) in plants: Mechanism of action. Indian J. Microbiol. 2007, 47, 289-297. [CrossRef]

57. Pieterse, C.M.; Zamioudis, C.; Berendsen, R.L.; Weller, D.M.; Van Wees, S.C.; Bakker, P.A. Induced systemic resistance by beneficial microbes. Annu. Rev. Phytopathol. 2014, 52, 347-375. [CrossRef]

58. Borowicz, V.A. The impact of arbuscular mycorrhizal fungi on plant growth following herbivory: A search for pattern. Acta Oecologica 2013, 52, 1-9. [CrossRef]

59. Russo, M.L.; Scorsetti, A.C.; Vianna, M.F.; Allegrucci, N.; Ferreri, N.A.; Cabello, M.N.; Pelizza, S.A. Effects of endophytic Beauveria bassiana (Ascomycota: Hypocreales) on biological, reproductive parameters and food preference of the soybean pest Helicoverpa gelotopoeon. J. King Saud. Univ. Sci. 2019, 31, 1077-1082. [CrossRef]

60. Jensen, R.E.; Enkegaard, A.; Steenberg, T. Increased fecundity of Aphis fabae on Vicia faba plants following seed or leaf inoculation with the entomopathogenic fungus Beauveria bassiana. PLoS ONE 2019, 14, e0223616. [CrossRef]

61. Clifton, E.H.; Jaronski, S.T.; Coates, B.S.; Hodgson, E.W.; Gassmann, A.J. Effects of endophytic entomopathogenic fungi on soybean aphid and identification of Metarhizium isolates from agricultural fields. PLoS ONE 2018, 13, e0194815. [CrossRef]

62. Kasajima, I.; Ebana, K.; Yamamoto, T.; Takahara, K.; Yano, M.; Kawai-Yamada, M.; Uchimiya, H. Molecular distinction in genetic regulation of nonphotochemical quenching in rice. Proc. Natl. Acad. Sci. USA 2011, 108, 13835-13840. [CrossRef]

63. Gawroński, P.; Witoń, D.; Vashutina, K.; Bederska, M.; Betliński, B.; Rusaczonek, A.; Karpiński, S. Mitogen-Activated Protein Kinase 4 Is a Salicylic Acid-Independent Regulator of Growth but Not of Photosynthesis in Arabidopsis. Mol. Plant 2014, 7 , 1151-1166. [CrossRef] [PubMed]

64. Hideg, V.; Spetea, C.; Vass, I. Singlet oxygen production in thylakoid membranes during photoinhibition as detected by EPR spectroscopy. Photosynth. Res. 1994, 39, 191-199. [CrossRef]

65. Krieger-Liszkay, A.; Fufezan, C.; Trebst, A. Singlet oxygen production in photosystem II and related protection mechanism. Photosynth. Res. 2008, 98, 551-564. [CrossRef] [PubMed]

66. Triantaphylidès, C.; Havaux, M. Singlet oxygen in plants: Production, detoxification and signaling. Trends Plant. Sci. 2009, 14, 219-228. [CrossRef]

67. Telfer, A. Singlet Oxygen Production by PSII Under Light Stress: Mechanism, Detection and the Protective role of $\beta$-Carotene. Plant Cell Physiol. 2014, 55, 1216-1223. [CrossRef]

68. Rasool, S.; Cárdenas, P.D.; Pattison, D.I.; Jensen, B.; Meyling, N.V. Isolate-Specific Effect of Entomopathogenic Endophytic Fungi on Population Growth of Two-Spotted Spider Mite (Tetranychus urticae Koch) and Levels of Steroidal Glycoalkaloids in Tomato. J. Chem. Ecol. 2021, 47, 476-488. [CrossRef] [PubMed]

69. Khan, A.L.; Hamayun, M.; Khan, S.A.; Kang, S.M.; Shinwari, Z.K.; Kamran, M.; Ur Rehman, S.; Kim, J.G.; Lee, I.J. Pure culture of Metarhizium anisopliae LHL07 reprograms soybean to higher growth and mitigates salt stress. World J. Microbiol. Biotechnol. 2012, 28, 1483-1494. [CrossRef]

70. Ahmad, I.; Jiménez-Gasco, M.D.M.; Luthe, D.S.; Shakeel, S.N.; Barbercheck, M.E. Endophytic Metarhizium robertsii promotes maize growth, suppresses insect growth, and alters plant defense gene expression. Biol. Control 2020, 144, 104167. [CrossRef]

71. Takahashi, S.; Badger, M.R. Photoprotection in plants: A new light on photosystem II damage. Trends Plant Sci. 2011, 16, 53-60. [CrossRef]

72. Li, X.P.; Muller-Moule, P.; Gilmore, A.M.; Niyogi, K.K. PsbS-dependent enhancement of feedback de-excitation protects photosystem II from photoinhibition. Proc. Natl. Acad. Sci. USA 2002, 99, 15222-15227. [CrossRef]

73. Dietz, K.-J.; Pfannschmidt, T. Novel Regulators in Photosynthetic Redox Control of Plant Metabolism and Gene Expression. Plant Physiol. 2011, 155, 1477-1485. [CrossRef]

74. Thomson, V.P.; Cunningham, S.A.; Ball, M.C.; Nicotra, A.B. Compensation for herbivory by Cucumis sativus through increased photosynthetic capacity and efficiency. Oecologia 2003, 134, 167-175. [CrossRef] [PubMed]

75. Lu, Y.; Yao, J. Chloroplasts at the Crossroad of Photosynthesis, Pathogen Infection and Plant Defense. Int. J. Mol. Sci. 2018, 19, 3900. [CrossRef] [PubMed]

76. Sanchez-Rodriguez, A.R.; Raya-Diaz, S.; Zamarreno, A.M.; Garcia-Mina, J.M.; del Campillo, M.C.; Quesada-Moraga, E. An endophytic Beauveria bassiana strain increases spike production in bread and durum wheat plants and effectively controls cotton leafworm (Spodoptera littoralis) larvae. Biol. Control 2018, 116, 90-102. [CrossRef]

77. Castillo, L.D.; Zhu-Salzman, K.; Ek-Ramos, M.J.; Sword, G.A. The Entomopathogenic Fungal Endophytes Purpureocillium lilacinum (Formerly Paecilomyces lilacinus) and Beauveria bassiana Negatively Affect Cotton Aphid Reproduction under Both Greenhouse and Field Conditions. PLoS ONE 2014, 9, e103891. [CrossRef]

78. Gupta, R.; Keppanan, R.; Leibman-Markus, M.; Rav David, D.; Elad, Y.; Ment, D.; Bar, M. The entomopathogenic fungi Metarhizium brunneum and Beauveria bassiana promote systemic immunity and confer resistance to a broad range of pests and pathogens in tomato. Phytopathology 2022. [CrossRef]

79. Cotes, B.; Thoming, G.; Amaya-Gomez, C.V.; Novak, O.; Nansen, C. Root-associated entomopathogenic fungi manipulate host plants to attract herbivorous insects. Sci. Rep. 2020, 10, 22424. [CrossRef] [PubMed] 
80. Steinwender, B.M.; Enkerli, J.; Widmer, F.; Eilenberg, J.; Kristensen, H.L.; Bidochka, M.J.; Meyling, N.V. Root isolations of Metarhizium spp. from crops reflect diversity in the soil and indicate no plant specificity. J. Invertebr. Pathol. 2015, 132, 142-148. [CrossRef]

81. Oxborough, K.; Baker, N.R. Resolving chlorophyll a fluorescence images of photosynthetic efficiency into photochemical and non-photochemical components—calculation of $\mathrm{qP}$ and Fv'/Fm' without measuring Fo'. Photosynth. Res. 1997, 54, 135-142. [CrossRef]

82. Bilger, W.; Björkman, O. Role of the xanthophyll cycle in photoprotection elucidated by measurements of light-induced absorbance changes, fluorescence and photosynthesis in leaves of Hedera canariensis. Photosynth. Res. 1990, 25, 173-185. [CrossRef] [PubMed]

83. Schreiber, U.; Bilger, W.; Neubauer, C. Chlorophyll fluorescence as a non-intrusive indicator for rapid assessment of in vivo photosynthesis. In Ecophysiology of Photosynthesis; Schulze, E.D., Caldwell, M.M., Eds.; Series Ecological Studies; Springer: Berlin, Germany, 1994; Volume 100, pp. 49-70.

84. Genty, B.; Briantais, J.M.; Baker, N.R. The relationship between the quantum yield of photosynthetic electron transport and quenching of chlorophyll fluorescence. Biochim. Biophys. Acta 1989, 990, 87-92. [CrossRef]

85. Bilger, W.; Schreiber, U.; Bock, M. Determination of the quantum efficiency of photosystem II and of non-photochemical quenching of chlorophyll fluorescence in the field. Oecologia 1995, 102, 425-432. [CrossRef] [PubMed] 